\title{
Study about the Effect of Sericin Finishing on the Performance of Sportswear
}

\author{
Xinyu Zhang', a \\ P.E Department, Harbin University of Science and Technology, Harbin, Heilongjiang, China
}

Keywords: sericin, sportswear, modification, textile, performance.

\begin{abstract}
The influence of sericin finishing on the air permeability, antistatic, uvioresistant, and hygroscopic and sweat releasing of the sportswear sold in the market after sericin finishing. The conclusion drawn from the research is that the antistatic property, uvioresistant property and hygroscopic and sweat releasing property are enhanced after sericin finishing but the sportswear's property will be affected if sericin is used to much because the movement of the fluid in the textile will be blocked if the textile is too thick. The research shows that the effect of sericin finishing becomes the best when the added sericin is $20 \mathrm{~g} / \mathrm{L}$ in the temperature of 45 ${ }^{\circ} \mathrm{C}$.
\end{abstract}

\section{Introduction}

The hygroscopic and sweat releasing property of the sportswear is of great importance because the people doing exercise would feel uncomfortable when the sweat which is caused by the increasing temperature in the body couldn't be released. The good garment materials can demonstrate its advantages and property to the greatest extent and make people feel more comfortable. The antistatic property, uvioresistant property and hygroscopic and sweat releasing property are the most important standard of a good sportswear. In this research the sportswear is modified by sericin finishing during which the sericin concentration and the finishing temperature are changed, which is of great value to the sportswear development.

\section{Material and finishing process}

\section{1 material and equipment}

Material: weft-knitted polyester fabric (sportswear sold in the market); sericin (Huzhou biomaterial limited company)

Equipment: YG461E digital air permeability meter (Wuhan national meter limited company); MMT liquid water meter (SDL Atlas); WV-2000 uvioresistant indexer for textile (Labsphere); EL - 400 vertical pneumatic padder; LD - 360 mini dryer (Shanghai Langgao textile equipment limited company); electronic balance (Xingyun electronic equipment limited company); measuring cylinder and so on. 


\section{2 sericin finishing experiment process}

Sericin finishing agent is used on sportswear. The sample to be tested is placed in the finishing agent and kept for $60 \mathrm{~min}$ in the specified temperature then it is took out and washed in room temperature. At last neutralizer is put into the sample and then the sample is dried after being washed. The technological parameter is shown in table 1 .

Table 1. sericin finishing technological parameter.

\begin{tabular}{cccc}
\hline Textile NO. & sericin dosage $/ \mathrm{g} \cdot \mathrm{L}^{-1}$ & $\begin{array}{c}\text { Glutaraidehyde dosage } \\
/ \mathrm{g} \cdot \mathrm{L}^{-1}\end{array}$ & temperature $/{ }^{\circ} \mathrm{C}$ \\
\hline 1 & sample & sample & sample \\
2 & 10 & 6 & 45 \\
3 & 20 & 6 & 45 \\
4 & 30 & 6 & 45 \\
5 & 40 & 6 & 45 \\
6 & 20 & 6 & 35 \\
7 & 20 & 6 & 45 \\
9 & 20 & 6 & 55 \\
\hline
\end{tabular}

\section{3 the test of the property of sportswear after sericin finishing and the discussion}

\section{1 adding weight}

$1^{\#} \sim 9^{\#}$ textile's weight increases $0.00,0.14,0.46,0.32,0.24,0.42,0.45,0.28,0.12 \mathrm{~g}$ respectively after sericin finishing as shown in table 2.

Table 2. weight of $1^{\#} \sim 9^{\#}$ textile after sericin finishing.

\begin{tabular}{cccccccccc}
\hline Textile NO. & 1 & 2 & 3 & 4 & 5 & 6 & 7 & 8 & 9 \\
\hline Addition/g & 0.00 & 0.14 & 0.46 & 0.32 & 0.24 & 0.42 & 0.45 & 0.28 & 0.12 \\
\hline
\end{tabular}

As is shown above with the concentration of sericin increasing the sericin in sportswear become more stimulated by glutaraldehyde but it becomes less after when the dosage is more than $29 \mathrm{~g} / \mathrm{L}$. It can be inferred that concentration of $20 \mathrm{~g} / \mathrm{L}$ is appropriate and the temperature of $45^{\circ} \mathrm{C}$ is the most proper according to $6^{\#} \sim 9^{\#}$ textile.

\section{2 air permeability test}

Air permeability test is performed by YG461E air permeability meter according to GB/T 5453 - 1997 the detection of textile air permeability with a nozzle whose diameter is $4 \mathrm{~mm}$. Air permeability of $1^{\#} \sim 9^{\#}$ textile is $1758,1739,1576,1582,1594,1718,1739,1702,1698 \mathrm{~mm} / \mathrm{s}$ respectively. 
From the test above it could be inferred that that air permeability has relationship with the addition of the sericin and the more the quantity of the sericin is, the less the air permeability is.

\section{3 antistatic test}

The test is performed according to the GB/T $12703.1-2008$ section 1 of assessment of textile antistatic property: static voltage half life period. The data is shown in table 3.

Table 3. the influence of sericin finishing on antistatic property

\begin{tabular}{ccc}
\hline Textile NO. & Static voltage/V & Half life period/S \\
\hline 1 & 1536 & 84.3 \\
2 & 1493 & 77.2 \\
3 & 1262 & 31.4 \\
4 & 1310 & 40.1 \\
6 & 1367 & 65.7 \\
7 & 1349 & 73.5 \\
8 & 1283 & 49.6 \\
9 & 1335 & 59.2 \\
\hline
\end{tabular}

It could be inferred that with the addition of the sericin in textile static property strengthens because the static voltage and half life period reduce which is caused by a lot of hydrophilic groups according to the table 3 .

\section{4 uvioresistant test}

This test is performed according to GB/T $18830-2009$ textile uvioresistant test. The data is shown in table 4.

Table 4. influence of the sercin finishing on ucioresistant property

\begin{tabular}{ccc}
\hline Textile NO. & T (UVA) & T (UVB) \\
\hline 1 & 10.05 & 8.32 \\
2 & 10.07 & 8.77 \\
3 & 10.65 & 9.16 \\
4 & 9.93 & 8.68 \\
5 & 9.85 & 8.65 \\
6 & 9.69 & 8.90
\end{tabular}


The ucioresistant of sportswear is strengthened after sericin finishing and the uciorestistant effect become more obvious with the addition of sericin in the textile according to the statistic shown in the table 4 .

\section{5 hygroscopic and sweat releasing property test}

The test is conducted according to the MMT test method in SN rules. The data are shown in Table 5.

Table 5. the influence of sercin finishing on hygroscopic and sweat releasing property

\begin{tabular}{|c|c|c|c|c|c|c|c|c|c|}
\hline item & $1^{\#}$ & $2^{\#}$ & $3^{\#}$ & $4^{\#}$ & $5^{\#}$ & $6^{\#}$ & $7^{\#}$ & $8^{\#}$ & $9^{\#}$ \\
\hline upper surface soaking hours/s & 4.875 & 4.746 & 4.547 & 4.594 & 4.653 & 4.596 & 4.578 & 4.546 & 4.860 \\
\hline Lower surface soaking hours/s & 4.501 & 4.501 & 4.498 & 4.513 & 4.554 & 4.446 & 4.448 & 4.558 & 4.343 \\
\hline $\begin{array}{l}\text { Upper surface water absortion } \\
\text { speed } / \% \cdot \mathrm{s}^{-1}\end{array}$ & 37.81 & 28.37 & 61.93 & 42.26 & 34.43 & 40.04 & 69.12 & 34.05 & 28.13 \\
\hline $\begin{array}{c}\text { Lower surface water absortion } \\
\text { speed } / \% \cdot \mathrm{s}^{-1}\end{array}$ & 26.29 & 19.33 & 42.27 & 41.54 & 31.04 & 31.17 & 64.59 & 22.74 & 18.03 \\
\hline $\begin{array}{l}\text { the maximum radius of upper } \\
\text { surface water absortion/mm }\end{array}$ & 22.5 & 25 & 25 & 25 & 25 & 25 & 25 & 25 & 25 \\
\hline $\begin{array}{l}\text { the maximum radius of lower } \\
\text { surface water absortion } / \mathrm{mm}\end{array}$ & 22.5 & 25 & 25 & 25 & 25 & 25 & 25 & 25 & 25 \\
\hline $\begin{array}{l}\text { The spreading speed of upper } \\
\text { surface liquid water } / \mathrm{mm} \cdot \mathrm{s}^{-1}\end{array}$ & 4.739 & 2.131 & 3.954 & 3.612 & 3.198 & 3.554 & 3.875 & 3.679 & 2.166 \\
\hline $\begin{array}{l}\text { The spreading speed of lower } \\
\text { surface liquid water } / \mathrm{mm} \cdot \mathrm{s}^{-1}\end{array}$ & 4.733 & 3.194 & 6.424 & 4.632 & 4.436 & 7.694 & 9.165 & 6.969 & 5.875 \\
\hline Unidirectional spreading index/\% & 687.3 & 548.7 & 793.9 & 702.3 & 626.5 & 736.9 & $\begin{array}{c}1118 . \\
2\end{array}$ & 956.4 & 772.2 \\
\hline $\begin{array}{c}\text { Dynamic spreading index of liquid } \\
\text { water }\end{array}$ & 0.765 & 0.741 & 0.839 & 0.838 & 0.776 & 0.714 & 0.902 & 0.817 & 0.772 \\
\hline
\end{tabular}

With the sericin in textile increasing the soaking hour become shorter which proves that the wettability increases which is caused by a large number of hydrophilic group in the surface according to the data shown in the table 5 . It could be inferred that the wicking ability increases according to the 
data of water absortion speed and the spreading speed of liquid water. The unidirectional spreading index reflects the water permeability. The sweat could flow to the outer surface (the lower surface) quickly when it meets the upper surface of the textile and evaporate from the outer surface which could keep the skin dry in the textile which has a higher unidirectional spreading index. The sweat releasing become better, which is indicated by the increasing index, with the increasing of the sericin. The dynamic spreading of liquid water becomes smoother, which is shown by its index in the test, after the sericin finishing.

\section{CONCLUSIONS}

4.1 From the above analysis the best technique of sericin finishing on sportswear could be concluded that the concentration of the sericin powder $20 \mathrm{~g} / \mathrm{L}$, temperature $45^{\circ} \mathrm{C}$, time $60 \mathrm{~min}$ and glutaraldehyde $6 \mathrm{~g} / \mathrm{L}$.

4.2 The air permeability, antistatic, uvioresistant, and hygroscopic and sweat releasing of the sportswear all become better while the air permeability changes little by using the best techqique mentioned above, which prove that the sericin which is mixed with cross-linking agent of glutaraldehyde is fixed on the surface of sportswear. With the usage of the waste sericin the water pollution could be reduced and the property of the sportswear becomes better.

\section{References}

1. Jin Li, Lili Mao: Manufacturing technique and design of knitwear, p. 165 (China textile press, Bejing 2001)

2. Jihong Chen, Jun Xiao: clothing materials and costume, p. 102-105 ( Donghua university press, Shanghai 2003)

3. Songwen Zhu: clothing material science(3rd edition), p. 63-68 (China textile press, Bejing 2001)

4. Huai Wang, Ruifeng Yang: clothing materials and application, p. 98-114(science and technology press, Liaoning 2005)

5. Haixiao Yin: research on wearability of the knitwear made by new type of acrylic fibers, p. 4243(Donghua University, Shanghai 2005)

6. Dali Ma, Yi Zhang, Jin Wang: detecting technology and practice of clothing material, p. 97(Chemical industry press, Beijing 2005)

7. Kenins P: influence of fiber type and moisture on measured fabric-to-skin friction, p. 146150(Textile Press, China 1994.(64))

8. Yongkai Zhou, Jianchun Zhang: The comfort and evaluation of the clothing, p. 14-18(Beijing craft press, Bejing 2006) 